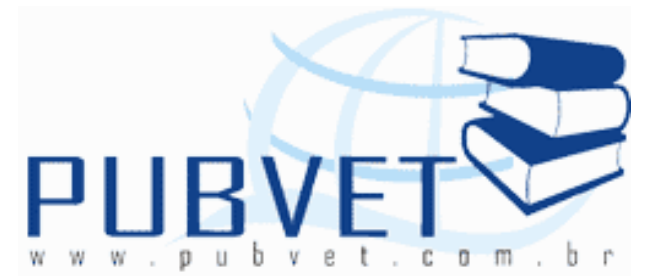

PUBVET, Publicações em Medicina Veterinária e Zootecnia.

\title{
Comportamento ingestivo de ovinos em pastos de diferentes estruturas
}

\footnotetext{
Verônica Bandeira Ferreira ${ }^{1 *}$, Leandro Ferreira Moreno $^{2}$, Ana Carolina Dalmaso ${ }^{1}$, Cláudio Jonasson Mousquer ${ }^{1}$, Amorésio Souza Silva Filho ${ }^{1}$, Alvair Hoffmann², Tiago Adriano Simioni², Wanderson José Rodrigues de Castro ${ }^{1}$

${ }^{1}$ Mestrandos do Programa de Pós-Graduação em Ciência Animal da Universidade Federal do Mato Grosso, Cuiabá-MT, Brasil.

${ }^{2}$ Mestrandos do Programa de Pós-Graduação em Zootecnia da Universidade Federal do Mato Grosso, Sinop-MT, Brasil.

*E-mail: veronica_zootecnista@yahoo.com.br
}

\section{Resumo}

Os ovinos são animais de hábito gregário e despendem momentos com a ingestão de alimentos intercalados com um ou mais períodos de ruminação ou de ócio. Os picos de pastejo e ruminação geralmente ocorrem nos horários mais frescos do dia, se mantendo em ócio nos horários de temperaturas mais elevadas. Estes animais modificam um ou mais componentes do seu comportamento ingestivo buscando superar condições limitantes ao seu consumo e conseguir as quantidades necessárias de nutrientes para à mantença e a produção. Desta maneira, esta revisão tem como objetivo debater estes itens que interferem no comportamento ingestivo de ovinos à pasto. O estudo do comportamento ingestivo coopera na solução de problemas 
FERREIRA, V.B. et al. Comportamento ingestivo de ovinos em pastos de diferentes estruturas.

PUBVET, Londrina, V. 8, N. 10, Ed. 259, Art. 1719, Maio, 2014.

relacionados com a diminuição do consumo em períodos críticos para produção de leite ou carne, através das práticas de manejo, dimensionamento das instalações e fornecimento de dieta com quantidade e qualidade.

Palavras-chave: Ruminantes. Comportamento animal. Hábito alimentar. Zootecnia.

\section{Sheep's intake behavior on different structures grass}

\section{Abstract}

Sheep are gregarious animals and spend time with food intake inserted with one or more periods of rumination or leisure. The peaks of grazing and ruminating usually happen in the cooler hours of the day, keeping in idle at times of higher temperatures. These animals modify one or more components of their ingestive behavior seeking to overcome limiting conditions for their consumption and get the necessary amounts of nutrients for the maintenance and production. Thus, this review has as an objective to discuss these items that affect the sheep's intake behavior at pasture. The feeding behavior study cooperates in solving problems related to the decrease in consumption in critical times for milk or meat, through of management practices, installation design and supply diet with quantity and quality.

Keywords: Ruminants. Animal behavior. Feeding habit. Forage. Animal Science.

\section{INTRODUÇÃO}

Os ovinos e os caprinos foram os primeiros animais domesticados pelo homem capazes de produzir alimentos. Estes animais têm participado da evolução da humanidade fornecendo leite, carne, pele, pêlo e lã e já foram encontrados em inúmeros achados arqueológicos, citados em passagens bíblicas, mitológicas e expressões folclóricas (Ribeiro e Ribeiro, 2005).

Apesar da importância social e econômica da ovinocultura, ainda são predominantes os sistemas extensivos e ultra extensivos de produção tendo 
FERREIRA, V.B. et al. Comportamento ingestivo de ovinos em pastos de diferentes estruturas.

PUBVET, Londrina, V. 8, N. 10, Ed. 259, Art. 1719, Maio, 2014.

como base alimentar o pasto, o que proporciona baixos índices produtivos e baixa rentabilidade para a propriedade (Moreira et al., 2008; Voltolini et al., 2009).

A espécie forrageira que constitui 0 pasto e suas características morfológicas de crescimento como altura, estrutura do relvado, idade, densidade, valor nutricional, relação folha:colmo, digestibilidade, aceitabilidade pelo animal, quantidade de material morto e características do terreno influenciam no comportamento dos ovinos em pastejo (Ribeiro et al, 2000), alterando os processos de colheita de forragem pelo aumento ou diminuição nos tempos de apreensão e manipulação da mesma (Silva, 2006).

O comportamento ingestivo é uma função da resposta animal às características da estrutura do pasto, obtido pelo conhecimento de três variáveis: tempo de pastejo, taxa de bocado e tamanho de bocado (Allden; Whittaker, 1970), que alteram as características morfológicas e fisiológicas do dossel forrageiro modificando os padrões de respostas de plantas e animais (Silva, 2006). Dessa forma, o conhecimento e entendimento das relações entre plantas e animais em sistemas à pasto tornam-se indispensáveis para estabelecer estratégias equilibradas e sustentáveis de manejo. Nesta revisão será abordado o comportamento ingestivo de ovinos quando submetidos à pastejo em pastos de diferentes estruturas.

\section{PRODUÇÃO DE OVINOS À PASTO}

Os ovinos possuem uma grande capacidade de adaptação às mais distintas condições de ambiente, permitindo sua criação em várias regiões do mundo pela sua facilidade de adaptação (Cunha et al., 1997).

São animais de porte baixo, cabeça pequena, boca com lábios móveis e ágeis favorecendo a escolha de partes mais ricas dos vegetais como folhas e brotos, são extremamente seletivos e caminham pela pastagem em busca das partes mais nutritivas das plantas (Van Soest, 1987; Vieira, 1994).

De acordo com Hulet et al. (1975) os lábios e os pequenos dentes incisivos são as estruturas de apreensão de alimentos para estes animais. Não 
FERREIRA, V.B. et al. Comportamento ingestivo de ovinos em pastos de diferentes estruturas.

PUBVET, Londrina, V. 8, N. 10, Ed. 259, Art. 1719, Maio, 2014.

há dentes incisivos superiores, portanto as folhas e caules são arrancados pelos dentes incisivos inferiores, com o animal exercendo movimentos com a cabeça para o lado e para cima.

São animais de hábito gregário, ou seja, estes andam em bando e necessitam ver uns aos outros enquanto pastejam (Forbes, 1995) e despedem períodos com a ingestão de alimentos intercalados com um ou mais períodos de ruminação ou de ócio (Gonçalves et al., 2001).

Na produção ovina em pastagens, é necessário que a escolha da planta forrageira seja feita de forma criteriosa, pois a mesma deve ser adequada às condições de clima e solo locais, da mesma forma que o manejo que será imposto, pois a área a ser implantada deve ter uma longa vida útil (Quadros, 2006).

A produção de forragem é dependente do meio físico (temperatura e radiação) e de fatores manejáveis, basicamente nutrientes e água (Nabinger, 1999). Segundo Gonçalves (2002) a maior dificuldade no ambiente de pastejo é manter a área foliar suficiente para garantir a interceptação eficaz da luz incidente e colher a forragem produzida eficientemente e com o melhor valor nutritivo possível, reduzindo as perdas por senescência. Neste panorama, encontra-se o maior problema da produção animal em pastagens, que é encontrar o balanço ótimo entre as exigências concorrentes de plantas e animais.

De forma geral, três condições básicas devem ser atendidas para a obtenção de uma alta produção animal: produção de uma grande quantidade de forragem com bom valor nutritivo, os animais devem colher grande proporção da forragem produzida e elevada eficiência de conversão dos animais, proporcionando um equilíbrio harmônico entre as três etapas da produção: crescimento, utilização e conversão (Hodgson, 1990).

\section{A estrutura do pasto e o consumo de forragem}

A estrutura de uma pastagem é uma característica fundamental e determinante tanto da dinâmica de crescimento e competição nas 
FERREIRA, V.B. et al. Comportamento ingestivo de ovinos em pastos de diferentes estruturas.

PUBVET, Londrina, V. 8, N. 10, Ed. 259, Art. 1719, Maio, 2014.

comunidades vegetais quanto do comportamento ingestivo dos animais em pastejo (Carvalho et al., 2001).

Os animais à pasto procuram e escolhem seu alimento, o qual pode se apresentar segundo diferentes tipos de estrutura, com qualidade e abundância variável (O'regain e Schwartz, 1995), neste ambiente com diferentes tipos e estruturas, os herbívoros desenvolveram uma série de mecanismos de pastejo que constituem o denominado comportamento ingestivo (Carvalho et al., 1999). Segundo Belovsky et al. (1999) estes mecanismos desenvolvidos pelos animais ao longo dos anos, permite que os mesmos colham uma dieta de qualidade superior àquela presente na média no ambiente.

Em cada fase da vida da planta, a natureza da matéria seca apresenta diferentes proporções de folhas, colmos, inflorescência e material morto, demonstrando que a composição da estrutura do pasto se altera ao longo do tempo (Medeiros et al., 2007) (Tabela 1).

Tabela 1 - Oferta de folhas verdes (OFV) e massas de forragem (MF), massa de folhas verde (MFV) e de material morto (MM) da pastagem de azevém anual em três estádios fenológicos.

\begin{tabular}{lccccc}
\hline $\begin{array}{c}\text { Estádio } \\
\text { fenológico }\end{array}$ & $\begin{array}{c}\text { OFV } \\
(\mathbf{P V} \%)\end{array}$ & $\begin{array}{c}\text { MF (kg } \\
\mathbf{M S} / \mathbf{h a})\end{array}$ & $\begin{array}{c}\text { MFV } \\
\mathbf{( \% )}\end{array}$ & $\begin{array}{c}\text { Colmo } \\
\mathbf{( \% )}\end{array}$ & $\begin{array}{c}\text { MM } \\
\mathbf{( \% )}\end{array}$ \\
\hline Vegetativo & $9,6 \mathrm{a}$ & $1610 \mathrm{a}$ & $68 \mathrm{a}$ & $18 \mathrm{a}$ & $13 \mathrm{a}$ \\
Pré-florescimento & $6,56 \mathrm{a}$ & $2235 \mathrm{~b}$ & $48 \mathrm{~b}$ & $34 \mathrm{~b}$ & $18 \mathrm{~b}$ \\
Florescimento & $5,46 \mathrm{a}$ & $3408 \mathrm{c}$ & $22 \mathrm{c}$ & $38 \mathrm{~b}$ & $40 \mathrm{c}$
\end{tabular}

Valores com letras iguais, na mesma coluna, não diferem pelo teste DMS a 5\% de significância. Fonte: Medeiros et al. (2007).

Segundo Minson (1990) os animais ruminantes apresentam maior preferência pelas folhas em relação aos colmos, pelo fato de que as folhas apresentam uma composição química melhor do que a dos colmos, em função da sua maior concentração de proteína e menor conteúdo de parede celular, ao menor gasto de energia para sua colheita em relação aos colmos e pela sua 
FERREIRA, V.B. et al. Comportamento ingestivo de ovinos em pastos de diferentes estruturas.

PUBVET, Londrina, V. 8, N. 10, Ed. 259, Art. 1719, Maio, 2014.

menor resistência à quebra pela mastigação e menor tempo de retenção no rúmen.

A relação folha:colmo é essencial para a nutrição animal e para o manejo de forrageiras, a maior participação de folhas ou de colmos na composição da matéria seca modifica o valor nutritivo da forragem. A alta relação folha:colmo geralmente representa forragem de bom valor nutritivo, com elevado teor de proteína, digestibilidade e consumo (Wilson, 1982).

Gordon e Illius (1992) mostrou a resposta funcional curvilinear clássica que relaciona o efeito da estrutura da pastagem sobre a ingestão de forragem por animais em pastejo, onde há um aumento da ingestão à medida que aumenta a quantidade de forragem presente na pastagem até um ponto de estabilização, representado pela saturação do animal em processar o alimento (Figura 1).

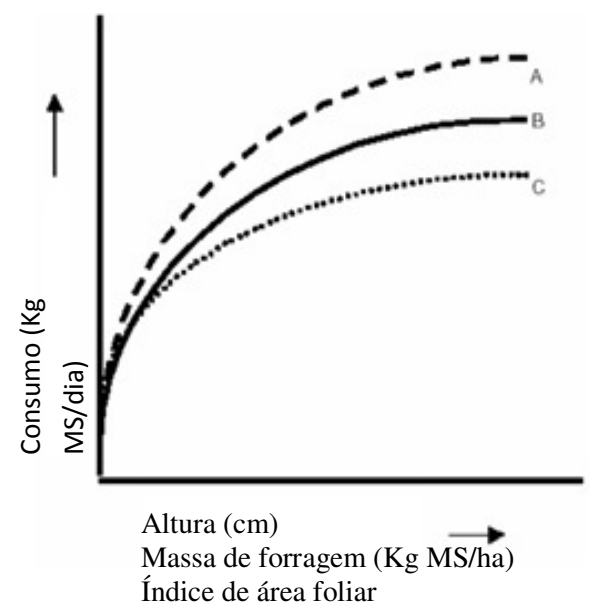

Figura 1 - Relação entre parâmetros da pastagem e o consumo de forragem. Há um aumento do consumo com a maior oferta de forragem e esta relação é curvilinear, ou seja, ponto de máxima que reflete a saturação do animal em processar o alimento. As curvas A, B e C indicam diferentes níveis de consumos para uma mesma altura, massa de forragem ou índice de área foliar, atribuídas a diferenças na arquitetura ou qualidade intrínseca das plantas, ou mesmo com animais de diferentes condições corporais e potenciais genéticos. Fonte: adaptado de Carvalho et al. (2000). 
FERREIRA, V.B. et al. Comportamento ingestivo de ovinos em pastos de diferentes estruturas.

PUBVET, Londrina, V. 8, N. 10, Ed. 259, Art. 1719, Maio, 2014.

Diferentes níveis de ingestão de matéria seca podem ser obtidos numa mesma quantidade de massa de forragem disponível. Isto ocorre porque, uma mesma massa de forragem pode se apresentar ao animal de diferentes formas por meio de inúmeras combinações entre altura e densidade para um mesmo tempo (Carvalho, 1997).

\section{O COMPORTAMENTO INGESTIVO E OS FATORES QUE O AFETAM}

Existem vários fatores que exercem influência sobre o comportamento ingestivo, como os relacionados ao próprio animal, ao ambiente, ao manejo e a forragem disponível. Para Brâncio et al. (2003), esta interação pode ser medida através de três parâmetros: tamanho do bocado, taxa de bocado e tempo de pastejo (Figura 2).

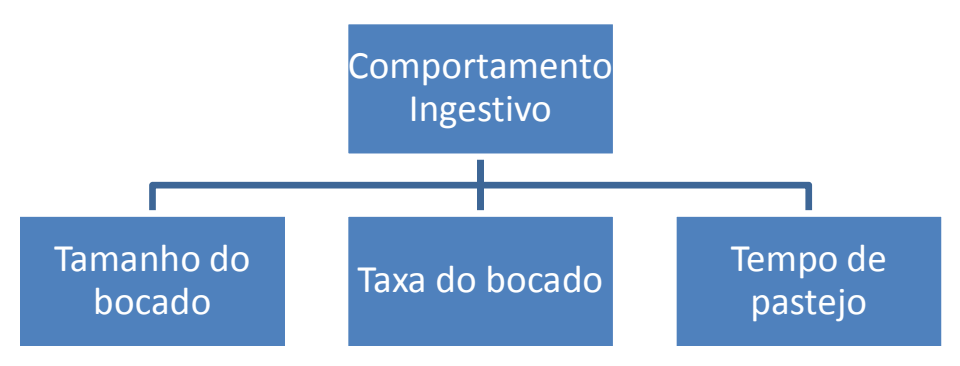

Figura 2. Principais componentes do comportamento ingestivo. Fonte: Adaptado de Brâncio et al. (2003).

Segundo Sarmento (2003) uma série de inter-relações caracteriza o ecossistema pastoril e uma delas se refere à interface planta-animal, regida por relações causa:efeito onde diferentes estruturas do dossel forrageiro determinam padrões distintos de comportamento e desempenho animal.

O consumo de dietas com alta densidade calórica é definida pela demanda energética do animal (regulação fisiológica), ao passo que o consumo de dietas de baixo valor nutritivo e baixa densidade energética é determinado pela capacidade física do trato gastrintestinal (regulação física) (Van Soest, 1994). 
FERREIRA, V.B. et al. Comportamento ingestivo de ovinos em pastos de diferentes estruturas.

PUBVET, Londrina, V. 8, N. 10, Ed. 259, Art. 1719, Maio, 2014.

A estrutura e composição botânica do dossel podem exercer um efeito direto sobre o consumo de forragem dos animais em pastejo, independente da influência da sua composição química e conteúdo de nutrientes (Hodgson, 1990).

A ingestão diária de forragem é produto do tempo gasto pelo animal em pastejo e a taxa de ingestão de forragem durante este período, que por sua vez é resultado do produto entre o número de bocados por unidade de tempo e a quantidade de forragem apreendida por bocado (Erlinger et al., 1990).

A seleção da dieta envolve a escolha de um local de pastejo seguido da seleção do bocado (Poppi, 1987). A seleção do local de pastejo é influenciada pela espécie da planta, estágio de maturidade e deposição de fezes e urina, além de fatores relacionados a variações na micro-topografia, abrigos, alinhamento de cercas e sombra, já a seleção do bocado é influenciada pela preferência do animal por componentes da planta, sua acessibilidade e abundância (Roman, 2006).

Os ovinos tendem a ter uma menor taxa de bocados e um maior tempo de pastejo que bovinos, devido provavelmente à uma maior seletividade de pastejo (Hodgson, 1990).

\section{Tamanho do bocado}

Considera-se como bocado o ato de apreender a forragem. O consumo total é a quantidade de forragem ingerida devido a frequência de bocados executados pelos animais e está diretamente relacionado com o desempenho (Carvalho e Moraes, 2005).

Dentre as variáveis que afetam a profundidade do bocado há as características estruturais do dossel como altura, estrutura e massa de forragem (Burns e Sollenberger, 2002). As dimensões do bocado (área e profundidade) de animais em pastejo são importantes tanto para a planta quanto para o animal. No caso das plantas, elas definem a profundidade e área da camada de forragem removida, definindo a intensidade e o padrão espacial de desfolhação (Edwards et al., 1995). 
FERREIRA, V.B. et al. Comportamento ingestivo de ovinos em pastos de diferentes estruturas.

PUBVET, Londrina, V. 8, N. 10, Ed. 259, Art. 1719, Maio, 2014.

Para o animal, a dimensão do bocado junto com a densidade da camada pastejada, define a massa do bocado que é a variável de maior influência no consumo animal (Coleman, 1992). A principal maneira de quantificar o consumo animal em pastejo é normalmente determinando a massa do bocado (Cosgrove, 1997).

A profundidade do bocado corresponde à diferença entre a altura inicial e a altura residual medida após o pastejo, e a área do bocado seria a área total pastejada dividida pelo número de bocados realizados (Ungar, 1996). Vários estudos concluíram que a profundidade do bocado apresenta uma relação positiva com a altura do pasto e negativa em relação à densidade da forragem.

Carvalho et al. (2001) observaram que a baixa disponibilidade de forragem afeta negativamente a massa de bocado, aumentando o tempo de pastejo e a taxa de bocado. Silva (2006) informa que a profundidade do bocado pode responder de maneira linear e positiva ao aumento na altura do pasto e Silveira (2001) propôs que quanto maior fora profundidade do bocado, maior será a massa do bocado, proporcionalmente à altura da pastagem, visto que, de acordo com Carvalho et al. (1999), ovinos removem cerca de 50\% da altura da pastagem por bocado.

O tamanho do bocado declina com o aparecimento das flores das plantas, esse declínio ocorre porque o tamanho do mesmo é reduzido para que o animal torne-se mais seletivo, pelo fato de grande parte dos nutrientes da planta ter sido transferida para as flores, conforme Pedroso (2004) (Tabela 2).

Assim pode-se deduzir que o pastejo seletivo é a maior causa do declínio do tamanho do bocado podendo a altura influir na massa e área do bocado (Forbes, 1995). 
FERREIRA, V.B. et al. Comportamento ingestivo de ovinos em pastos de diferentes estruturas.

PUBVET, Londrina, V. 8, N. 10, Ed. 259, Art. 1719, Maio, 2014.

Tabela 2 - Comportamento ingestivo de ovelhas em pastejo de azevém anual em diferentes estádios fenológicos.

\begin{tabular}{lcccc}
\hline $\begin{array}{c}\text { Estádio } \\
\text { Fenológico }\end{array}$ & $\begin{array}{c}\text { Taxa de } \\
\text { Pastejo } \\
\text { (h/dia) }\end{array}$ & $\begin{array}{c}\text { Taxa de } \\
\text { bocado } \\
\text { (boc/min) }\end{array}$ & $\begin{array}{c}\text { Peso do } \\
\text { bocado } \\
\text { (g/boc) }\end{array}$ & $\begin{array}{c}\text { Consumo de } \\
\text { de forragem } \\
\text { (\%o PV) }\end{array}$ \\
\hline Vegetativo & $9,61 \mathrm{a}$ & $52,65 \mathrm{a}$ & $0,06 \mathrm{a}$ & $4,48 \mathrm{a}$ \\
Pré-florescimento & $10,97 \mathrm{~b}$ & $51,93 \mathrm{a}$ & $0,05 \mathrm{~b}$ & $3,91 \mathrm{~b}$ \\
Florescimento & $10,68 \mathrm{~b}$ & $40,63 \mathrm{~b}$ & $0,04 \mathrm{c}$ & $2,72 \mathrm{c}$ \\
\hline
\end{tabular}

Valores com letras iguais na mesma coluna não diferem entre si pelo teste DMS a 5\% de significância. Fonte: Pedroso (2004).

\section{Taxa de bocado}

A taxa de bocado é uma das ferramentas utilizadas para determinar o comportamento de ingestão de forragem pelos animais no pasto (Rodrigues, 2010).

Segundo Carvalho et al. (2001) a taxa de bocado é uma variável que é correlacionada negativamente à massa do bocado, pois quanto maior a massa do bocado realizada pelo animal menor será a taxa, porque os movimentos mandibulares de manipulação (apreensão e mastigação) serão maiores.

A altura também se correlaciona com a taxa de bocado do animal em pastejo, quanto mais alto é o pasto maior será o tempo do bocado, pois maiores serão os movimentos manipulativos (Carvalho et al., 2001).

A quantidade de forragem ingerida diariamente é o produto entre o tempo de pastejo e a taxa de ingestão de forragem durante o pastejo. A taxa de ingestão de forragem é o produto entre a taxa de bocados e o tamanho dos bocados (Carvalho, 1997).

A frequência média dos bocados de apreensão está ligada a características inerentes à estrutura do dossel forrageiro, mas também possui íntima ligação com o tamanho de bocado que é o determinante da quantidade de alimento consumida pelo animal (Hodgson et al., 1990; Cosgrove, 1997). Esses reflexos podem ser observados muitas vezes como resposta a reduções 
FERREIRA, V.B. et al. Comportamento ingestivo de ovinos em pastos de diferentes estruturas.

PUBVET, Londrina, V. 8, N. 10, Ed. 259, Art. 1719, Maio, 2014.

na oferta de forragem, altura do dossel forrageiro, densidade volumétrica e redução da proporção de folhas verdes (Stobbs, 1973).

Segundo Penning et al. (1991) o número total de movimentos mandibulares de um animal ao longo do dia tem se revelado semelhante, podendo existir variações quanto à quantidade de movimentos mandibulares destinados à apreensão e manipulação da forragem. A teoria de que o animal aumentaria a taxa de bocados na tentativa de compensar a diminuição do peso do bocado se explicaria, na verdade, por uma estratégia do animal de diminuição do número de bocados de mastigação, mantendo o número total de movimentos mandibulares. Em ocasião contrária onde a massa de bocado é alta, maior será a necessidade de mastigação e, portanto, o número de bocados de apreensão deve ser reduzido (Ungar, 1996), sendo esta uma possível explicação para algumas circunstâncias onde o aumento no tamanho do bocado não afeta a taxa de consumo instantânea (Hodgson et al., 1994).

Segundo Carvalho et al. (2001) o número de bocados realizados por ruminantes no período de um dia pode facilmente alcançar a faixa de 35.000 ações, com duração de cada bocado variando de um a dois segundos. Em condições com baixa disponibilidade de massa de forragem os ovinos realizam até 65 bocados por minuto, diferente do que acontece quando existe oferta suficiente, onde esta frequência pode reduzir pela metade (Delegarde et al., 2001).

Segundo Carvalho e Moraes (2005) quanto maior for a taxa de bocados, ou seja, quanto maior o número de ações em menos tempo, maior a probabilidade do animal estar em condições de limitação de consumo e possivelmente não alcançará a sua saciedade. Silva et al. (2007) também observaram que quanto menor a oferta de pasto e o número de perfilhos, maior a taxa de bocados indicando que os animais tentam compensar a disponibilidade limitada.

Segundo Pedroso et al. (2004), quando ocorre maior proporção de folhas na pastagem há um incremento na taxa e peso de bocados. Por outro lado, em 
FERREIRA, V.B. et al. Comportamento ingestivo de ovinos em pastos de diferentes estruturas.

PUBVET, Londrina, V. 8, N. 10, Ed. 259, Art. 1719, Maio, 2014.

momentos que a forragem não apresenta elevada quantidade de folhas as ovelhas reduzem o peso de bocados, aumentam intervalo entre estes e o tempo total de pastejo, indicando preferência por material de qualidade. Em situações onde a maioria dos animais de um lote está em pastejo ao mesmo tempo a concorrência para consumir a forragem também promove um aumento na taxa e peso de bocados (Medeiros et al., 2007).

Segundo Trevisan et al. (2004), a medida da taxa de bocados estima com que facilidade ocorrem apreensões de forragem, o que, aliado ao tempo dedicado pelo animal ao pastejo, bem como a profundidade e massa de bocados, integram as relações planta-animal responsáveis por determinada quantidade de forragem consumida.

\section{Tempo de pastejo}

Os ovinos despendem seu tempo basicamente em três atividades: busca do alimento, ruminação e ócio. Portanto, a colheita do alimento é dependente do gasto de energia pelo animal e se a estrutura da pastagem não estiver adequada para o alcance do bocado, o animal gastará muito em sua energia de mantença (Zanine et al., 2006). Neste contexto, deve-se adequar o estabelecimento e o manejo das pastagens ao hábito alimentar do animal, de forma que ele consiga suprir sua capacidade máxima de ingestão no menor espaço de tempo possível, levando em conta à altura e a densidade da gramínea (Fraser, 1980).

Vários fatores podem influenciar o tempo gasto no pastejo por estes animais, devido à necessidade de desenvolver certas atividades como ruminar, beber água, descansar e socializar, o tempo que fica destinado ao pastejo é limitado (Silveira, 2001). O tempo despendido com a ingestão está diretamente relacionado com a disponibilidade e com a qualidade do alimento oferecido (Rutter et al., 2002).

Quando expostos à alimentação ad libitum, os ovinos apresentaram um padrão predominantemente diurno (Gill, 2004). Segundo Jensen (2002), os animais preferem este período, evitando a noite, provavelmente por ser uma 
FERREIRA, V.B. et al. Comportamento ingestivo de ovinos em pastos de diferentes estruturas. PUBVET, Londrina, V. 8, N. 10, Ed. 259, Art. 1719, Maio, 2014.

resposta adaptativa anti-predador e por poderem ver seu alimento. No inverno ocorre maior tempo de alimentação no escuro, pois os dias são mais curtos e não permitem que os animais atendam suas necessidades durante o dia. Sob condições de iluminação natural, em latitudes onde é marcado um ritmo anual de fotoperíodo, os ovinos apresentam um ciclo diário de alimentação durante o ano, com um pico no tempo de ingestão poucas semanas depois do dia mais longo e uma queda após o dia mais curto do ano (Forbes, 1995).

Conforme verificado por Silveira (2001), o número de refeições realizadas por cordeiros variou entre seis ao longo do dia, durando cerca de 40 minutos cada uma delas. Entretanto, para Cosgrove (1997), os ovinos geralmente distribuem a sua alimentação durante o dia em três à cinco períodos de pastejo os mais intensos ocorrendo no início da manhã e no final da tarde. Esta pode ser considerada uma variável inversamente relacionada ao consumo, ou seja, quanto maior a disponibilidade de forragem menor será o tempo total de pastejo, maior o número de refeições curtas realizadas de forma intercalada, com intervalos mais longos entre refeições (De Paula et al., 2010). Os ovinos quando encontram forragem altamente nutritiva gastam menos tempo para a atividade de pastejo e ingerem muito além dos seus requerimentos nutricionais. Carvalho e Moraes (2005) relataram que ovinos na presença de alta concentração de massa de forragem, com oferta abundante, realizam várias refeições de curta duração, caracterizadas por altas taxas de ingestão, resultando em enchimento rápido do rúmen.

Os picos de pastejo se concentram no início da manhã e no final do dia por conta de temperaturas mais amenas e os picos de ruminação se concentram logo após os picos de pastejo (Gill, 2004). Zanine et al. (2006) afirmaram que os animais permanecem ociosos nos horários mais quentes do dia como estratégia de melhor aproveitamento energético do alimento.

Van Soest (1994) afirmou que o tempo despendido em ruminação é influenciado pela natureza da dieta e é, provavelmente, proporcional ao teor 
FERREIRA, V.B. et al. Comportamento ingestivo de ovinos em pastos de diferentes estruturas. PUBVET, Londrina, V. 8, N. 10, Ed. 259, Art. 1719, Maio, 2014.

de parede celular dos volumosos de modo que, quanto maior o teor de fibra na dieta maior o tempo despendido em ruminação.

Ferreira et al. (2011) avaliando o comportamento de dois grupos de ovelhas Santa Inês, em pastos de capim-quicuio (Pennisetum clandestinum Hochst. cv. Comum) com sombra e sem sombra, observaram que os picos de pastejo se deram no período da manhã e no final da tarde e os períodos de ócio ocorrem nos horários mais quentes do dia (Tabela 3 e tabela 4).

Tabela 3. Comportamento de ovinos Santa Inês (em \% do tempo), mantidos em piquete com sol das 9 às 17 horas. PI (Período I), PII (Período II) e PIII (Período III).

\begin{tabular}{llcc}
\hline $\begin{array}{l}\text { Período } \\
\text { (horas) }\end{array}$ & \multicolumn{3}{c}{ Comportamento ao sol } \\
\hline Total $(09$ às $17 \mathrm{~h})$ & $83,0 \pm 1,05$ & $9,1 \pm 0,80$ & $7,9 \pm 0,75$ \\
\hline PI $(09$ às $11 \mathrm{~h})$ & $91,4 \pm 1,58$ & $4,6 \pm 1,18$ & $4,0 \pm 1,10$ \\
\hline PII (11 às 14h) & $70,0 \pm 2,06$ & $14,7 \pm 1,59$ & $15,3 \pm 1,61$ \\
\hline PIII (14 às 17h) & $91,0 \pm 1,31$ & $6,2 \pm 1,11$ & $2,8 \pm 0,75$ \\
\hline
\end{tabular}

Fonte: Adaptado de Ferreira et al. (2011).

Tabela 4. Comportamento de ovinos Santa Inês (em \% do tempo), mantidos em piquete com sombra das 9 às 17 horas. PI (Período I), PII (Período II) e PIII (Período III).

\begin{tabular}{lllc}
\hline \multicolumn{1}{c}{$\begin{array}{l}\text { Período } \\
\text { (horas) }\end{array}$} & \multicolumn{3}{c}{ Comportamento à sombra } \\
\hline Total (09 às 17h) & $91,6 \pm 0,77$ & $4,3 \pm 0,57$ & $4,0 \pm 0,54$ \\
\hline PI (09 às 11h) & $88,7 \pm 1,78$ & $6,6 \pm 1,40$ & $4,7 \pm 1,19$ \\
\hline PII (11 às 14h) & $94,1 \pm 1,05$ & $3,4 \pm 0,81$ & $2,5 \pm 0,70$ \\
\hline PIII (14 às 17h) & $91,0 \pm 1,32$ & $3,9 \pm 0,89$ & $5,1 \pm 1,01$ \\
\hline
\end{tabular}

Fonte: Adaptado de Ferreira et al. (2011).

O estudo da velocidade de ingestão relaciona-se diretamente com os efeitos da estrutura do pasto, estando o foco centrado no processo de ingestão da forragem, já o consumo diário estaria na dependência do tempo de pastejo que é função de uma série de fatores, como a taxa de passagem e a relação 
FERREIRA, V.B. et al. Comportamento ingestivo de ovinos em pastos de diferentes estruturas.

PUBVET, Londrina, V. 8, N. 10, Ed. 259, Art. 1719, Maio, 2014.

consumo/requerimento (Silva, 2006). Segundo Champion et al. (2004) os animais pastejam em torno de $10 \mathrm{~h}$ por dia e segundo Hodgson et al. (1990) o tempo de pastejo pode atingir até 16 horas em casos extremos, onde nesses casos o processo de digestão da forragem passaria a ter caráter mais importante (Laca e Demment, 1992).

O estádio fisiológico da planta pode influenciar o tempo de pastejo de ovelhas, como registraram Medeiros et al. (2007), avaliando pastagens de azevém anual em diferentes estádios fenológicos, vegetativo, préflorescimento e de florescimento (Tabela 5). No pré-florescimento, houve alta atividade de pastejo, as ovelhas elevaram a taxa de bocados e a quantidade de forragem coletada por bocado e diminuíram a qualidade do ingerido. No estádio de florescimento, reduziram os tempos de pastejo e o consumo de matéria seca e de proteína bruta ao longo de todo o período diurno, como consequência da baixa qualidade da forragem disponível e da estrutura da vegetação. A procura por lâminas foliares novas demanda maior tempo de pastejo, pois os animais precisam se locomover pelo pasto à procura destas (Bremm et al., 2008).

Tabela 5. Tempo de pastejo e consumo de matéria seca (MS), por ovinos em pastagem de azevém anual em diferentes estádios fenológicos.

\begin{tabular}{lcc}
\hline Estádio & Tempo de pastejo & Consumo de MS \\
Fenológico & $(\mathrm{min} / \mathrm{dia})$ & $(\mathrm{g} / \mathrm{dia})$
\end{tabular}

\begin{tabular}{lrr}
\hline Vegetativo & $321,66 \mathrm{a}$ & $1.078,01 \mathrm{a}$ \\
Pré-florescimento & $432,98 \mathrm{~b}$ & $917,824 \mathrm{a}$ \\
Florescimento & $425,96 \mathrm{~b}$ & $610,32 \mathrm{~b}$
\end{tabular}

Valores com letras iguais na mesma coluna não diferem pelo teste DMS a $5 \%$ de significância. Fonte: Adaptado de Medeiros (2007).

Natel et al. (2012) trabalhando com ovinos com quatro teores de FDN da dieta, observaram que os tempos despendidos com ingestão, ruminação e mastigação apresentam acréscimo com o aumento do nível de FDN. Foi 
FERREIRA, V.B. et al. Comportamento ingestivo de ovinos em pastos de diferentes estruturas.

PUBVET, Londrina, V. 8, N. 10, Ed. 259, Art. 1719, Maio, 2014.

observado aumento da ingestão nos animais submetidos a rações com até $32 \%$ de FDN, com maximização do consumo ao nível de $37,8 \%$ de FDN na ração. A partir deste valor, houve decréscimo no consumo.

O tempo de pastejo é a variável em que menos se tem gerado progressos em termos de conhecimento quando comparado com os outros processos determinantes do consumo diário (Gordon e Lascano, 1993).

\section{PREFERÊNCIA ALIMENTAR DOS OVINOS}

Os ovinos realizam uma avaliação visual antes de iniciarem o pastejo em um local, qualificando e quantificando a forragem disponível. Quando esta se encontra abaixo da média estabelecida, o animal busca um novo local que the garanta um melhor consumo de forragem (Palhano et al., 2002). Ao serem submetidos à restrição alimentar, os animais desenvolvem diferentes estratégias de pastejo para se adaptarem à nova condição do ambiente (Medeiros et al., 2007). De acordo com Gill (2004) a ingestão é motivada pela fome e esta, por sua vez é motivada pela demanda nutricional.

Hodgson (1990) definiu a preferência como a discriminação exercida pelos animais entre diferentes espécies ou componentes de pastos, quando não limitados em suas escolhas e a seleção como a remoção de alguns componentes do pasto mais que de outros.

Vários fatores podem influenciar a preferência, como altura, presença de material morto, proporção folha:colmo, resistência à tração, distribuição espacial, disponibilidade de matéria seca e intimidade com as forrageiras (Dumont, 1997). Segundo Ramirez (1989) os fatores que determinam a preferência estão relacionados a características da comunidade vegetal, dos animais, dos fatores climáticos e do manejo que se realiza no ecossistema; já as características dos animais em pastejo se definem por seu estado fisiológico, estado sanitário, idade, familiaridade com a pastagem e fatores genéticos. Monteiro et al. (2006), afirmaram que ovinos do ponto de vista nutricional são bastante seletivos, estes animais preferem folhas a caules e material suculento a seco, porém a fome tende a diminuir a seletividade. 
FERREIRA, V.B. et al. Comportamento ingestivo de ovinos em pastos de diferentes estruturas.

PUBVET, Londrina, V. 8, N. 10, Ed. 259, Art. 1719, Maio, 2014.

Os ovinos possuem preferência por altura, pois significa oportunidade de alta ingestão à medida que a altura potencializa a profundidade do bocado, que por sua vez é o principal determinante da massa do bocado (Carvalho et al., 2001). Contudo, pastos altos possuem maiores quantidades de carboidratos de baixa digestibilidade e Silveira (2001) observou que quanto maior a altura do pasto, maior o intervalo entre as refeições e maior o tempo destinado para as outras atividades. Com isso, estes componentes de menor qualidade demandam maior tempo para serem digeridos, gerando maior tempo de ruminação. Monteiro et al. (2006), concluíram também que a rejeição por pastos altos ocorre devido à preferência dos animais pelo extrato inferior das plantas, onde se encontram folhas novas e brotos, que são de maior digestibilidade.

E ainda, se tem o fato de que os ovinos apresentam comportamento gregário e têm a necessidade de visualizar os demais animais a sua volta, o que pode ser prejudicial em pastos de altura muito elevada, segundo Quadros (2006) a altura da pastagem não deve ultrapassar um metro, ou na prática, deve atingir no máximo a altura do focinho do animal, para promover à visualização uns dos outros.

Segundo Forbes (1995) os ovinos pastejam mantendo uma distância mínima do outro animal, sendo denominado de espaço individual, que é o espaço físico que o animal necessita para realizar os movimentos básicos, se esta distância não for respeitada a seletividade pode ser afetada.

Novais et al. (2009) trabalhando com ovinos em pastagem de capimmarandu submetidas à diferentes alturas, obteve um maior número e taxa de bocados para altura de $10 \mathrm{~cm}$ do dossel foram, possivelmente, devido à menor oferta de forragem. Tal fato demonstra que em alturas maiores o animal tem maior facilidade de apreender a forragem, necessitando de menor número de bocados para ingerir a quantidade de alimento necessária, com menor demanda de energia.

A quantidade de ingestão pode ainda variar conforme as estações do ano, no inverno a maior demanda energética pode aumentar a taxa de 
FERREIRA, V.B. et al. Comportamento ingestivo de ovinos em pastos de diferentes estruturas.

PUBVET, Londrina, V. 8, N. 10, Ed. 259, Art. 1719, Maio, 2014.

passagem do alimento permitindo maior ingestão de alimentos, suprindo a maior demanda e o efeito contrário pode ser observado durante o verão. 0 clima ainda pode ainda influenciar na escolha do que será ingerido, com as mudanças nas porcentagens de gramíneas, ervas e arbustos da época chuvosa para a seca (Figura 3) (Leão, 2005).

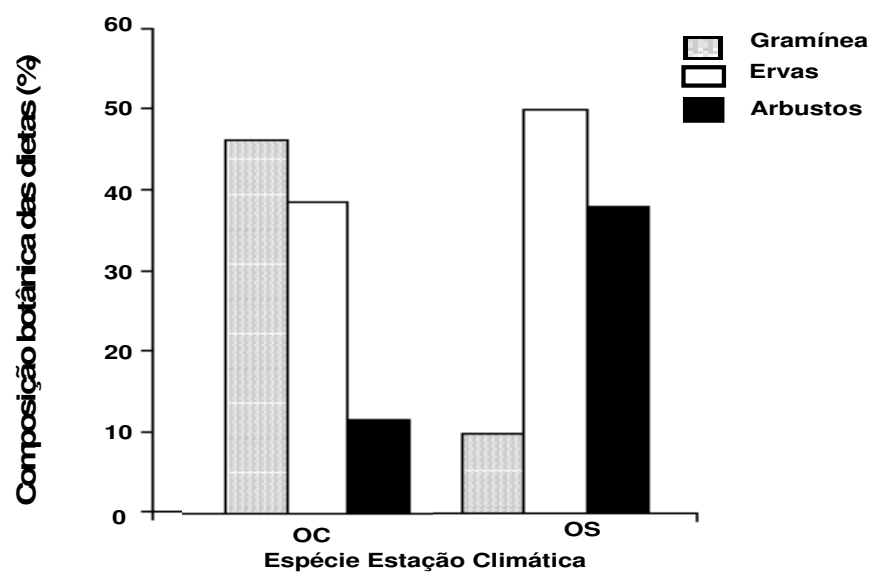

Figura 3 - Composição Botânica da dieta de ovinos (O) durante as estações, chuvosa(C) e seca(S). Fonte: Adaptado de Leão (2005).

\section{CONCLUSÃO}

O tempo de pastejo dos ovinos geralmente ocorre entre 6:00 e 11:00 horas, dependendo da estrutura e qualidade do pasto, os picos de pastejo ocorrem no início da manhã e no final do dia e os picos de ruminação logo após os picos de pastejo. Nos horários de maiores temperaturas, os ovinos permanecem em ócio como estratégia de melhor aproveitamento energético do alimento.

Observando os fatores que afetam o comportamento ingestivo dos ovinos, nota-se a importância de conhecer os seus hábitos para que se possa realizar um manejo mais adequado. Para a criação de ovinos é necessário o fornecimento de pastos de boa qualidade, com boa oferta de forragem, sempre considerando as interações entre planta-animal. Pesquisas científicas são necessárias para que as melhores respostas produtivas dos ovinos possam ser 
FERREIRA, V.B. et al. Comportamento ingestivo de ovinos em pastos de diferentes estruturas. PUBVET, Londrina, V. 8, N. 10, Ed. 259, Art. 1719, Maio, 2014.

encontradas com relação às taxas de lotação, níveis de suplementação, hábito de pastejo, facilitando o manejo das pastagens e gerando melhoras nos índices produtivos.

\section{REFERÊNCIAS BIBLIOGRÁFICAS}

ALLDEN, W. G.; WHITTAKER, M. The determinants of herbage intake by grazing sheeps: the interrelationship of factors influencing herbage intake and availability. Australian Journal of Agricultural Research, v. 21, n. 1, p. 755-766. 1970.

BELOVSKY, G. E., FRYXELL, J., SCHMITZ, O. J. Natural selection and herbivore nutrition: optimal foraging theory and what it tells us about the structure of ecological communities. In: JUNG, H. J. G., FAHEY Jr., G. C. (Eds.). Nutritional Ecology of Herbivores. Proceedings of the $\mathrm{V}$ th International Symposium on the nutrition of herbivores. San Antonio, USA. 1999. p.1-70.

BRÂNCIO, P. A et al. Avaliação de três cultivares de Panicum maximumJacq. sob pastejo: comportamento ingestivo de bovinos. Revista Brasileira de Zootecnia, v.32, n.5, p.10451053, 2003.

BREMM, C.; ROCHA, M. G. da; FREITAS, F. K. de; MACARI, S.; ELEJALDE, A. G.; ROSO, D. Comportamento ingestivo de novilhas de corte submetidas a estratégias de suplementação em pastagens de aveia e azevém. Revista Brasileira de Zootecnia, Viçosa, v. 37, n. 7, pp. 1161-1167. 2008.

BURNS, J. C.; SOLLENBERGER, L. E. Grazing behavior of ruminants and daily performance from warn- season grasses. Crop Sci., v. 42, p. 873- 881, 2002.

CARVALHO, P. C. F. A estrutura da pastagem e o comportamento ingestivo de ruminantes em pastejo. In: JOBIN, C. C.; SANTOS, G. T.; CECATO, U. (Ed.). SIMPÓSIO SOBRE AVALIAÇÃO DE PASTAGENS COM ANIMAIS, 1997, Maringá. Anais... Maringá: UEM, 1997b. p. 25-52.

CARVALHO, P. C. F.; PRACHES, S.; ROGUET, C.; LOUAULT, F. Defoliation process by ewes of reproductive compared to vegetative sward. In: INTERNATIONAL SYMPOSIUM ON THE NUTRITION OF HERBIVORES, 1999, San Antonio. Proceedings... San Antonio, 1999.

CARVALHO, P. C. F., POLI, C. H. E. C., NABINGER, C., MORAES, A. Comportamento ingestivo de bovinos em pastejo e sua relação com a estrutura da pastagem. In:FERRAZ, J.B.S. (Ed). PECUÁRIA 2000: A PECUÁRIA DE CORTE NO III MILÊNIO. Pirassununga, Anais...2000. CDROM.

CARVALHO, P. C. F.; MARÇAL, G. K.; RIBEIRO FILHO, H. M. N.; POLI, C. H. E. C.; TRINDADE, J. K.; OLIVEIRA, J. O. R.; NABINGER, C.; MORAES, A. Pastagens altas podem limitar o consumo dos animais. In: REUNIÃO ANUAL DA SOCIEDADE BRASILEIRA DE ZOOTECNIA, 38, 2001, Piracicaba. Anais... Piracicaba, 2001. p. 265-268.

CARVALHO, P. C. F.; MORAES, A. de. Comportamento ingestivo de Ruminantes: bases para o manejo sustentável do pasto. In: ULYSSES CECATO; CLÓVES CABREIRA JOBIM. (Org.). Manejo Sustentável em Pastagem. Maringá-PR. Anais.... Maringá-PR: Universidade Estadual de Maringá, v. 1, p. 1-20, 2005.

CHAMPION, R. A. et al. The effect of the spatial scale of heterogeneity of two herbage species on the grazing behaviour of lactating sheep. Applied Animal Behaviour Science, v. 88, n.12, p.61-76, 2004. 
COLEMAN, S. W. Plant-Animal interface. Journal of Production Agriculture, v. 5, p.7-13. 1992.

COSGROVE, G. P. Grazing behavior and forage intake. In: INTERNATIONAL SYMPOSIUM ON ANIMAL PRODUCTION UNDER GRAZING, 1., 1997, Viçosa, MG. Anais... Viçosa, MG: Universidade Federal de Viçosa, p.59-80, 1997.

CUNHA, E. A.; SANTOS, L. E.; RODA, D. S.; POZZI, C.R.; OTSUK, I. P.; BUENO, M.S.; RODRIGUES, C. F. C. Efeito do sistema de manejo sobre o comportamento em pastejo, desempenho ponderal e infestação parasitária em ovinos suffolk. Pesquisa Veterinária Brasileira, v. 17, n. 3-4, p. 1005-1011, 1997.

DELEGARDE, R.; PRACHE, S.; D'HOUR, P.; PETIT, M. Ingestion de 1 'h erbe par les ruminanst au pasturage. In: Nouveaux regard sur le pasturage. Association Française pour la Production Fourragère. Proceedings... p.53-68. 2001.

DUMONT, B. Diet preferences of herbivores at pastures. Annales de Zootechnie, Paris, v. 46, p. 105-116, 1997.

EDWARDS, G. R.; PARSONS, A. J.; PENNING, P. D.; NEWMAN, J. A. Relationship between vegetation state and bite dimensions of sheep grazing contrasting plant species and its implications for intake rate and diet selection. Grass and Forage Science, Oxford, v. 50, p. 378-388. 1995.

ERLINGER, L. L.; TOLLESON, D.; BROWN, C. J. Comparsion of bite size, biting rate and grazing time of beef heifers from herds distinguished by mature size and rate of maturity. Journal of Animal Science, v. 68, n. 3, p. 3578-3587. 1990.

FERREIRA, R. A.; ESTRADA, L. H. C.; THIÉBAUT, J. T. L.; GRANADOS, L. B. C.; SOUZA JÚNIOR, V. R. Avaliação do comportamento de ovinos Santa Inês em sistema silvipastoril no norte fluminense. Ciênc. agrotec., Lavras, v. 35, n. 2, p. 399-403, 2011.

FORBES, J. M. Voluntary food intake and diet selection in farm animals. London, Centre for Agricultural and Biosciences Internacional, 1995. 532p.

FRASER, A. F. Comportamiento de los animales de la granja. Zaragoza: Acribia, 1980. 291p.

GILL, W. Applied sheep behaviour - Agricultural Extension Service, The University of Tennessee. Disponível em:<http://animalscience.ag.utk.edu/sheep/pdf/appliedsheepbehavior-wwg-2-04.pdf>, 2004, p. 15 - 19. Acessado em 18/10/2013.

GONÇALVES, A.L.; LANA, R.P.; RODRIGUES, M.T.; VIEIRA, R.A.M.; QUEIROZ, A.C.; HENRIQUE, D.S. Padrão nictemeral do pH ruminal e comportamento alimentar de cabras leiteiras alimentadas com dietas contendo diferentes relações volumoso:concentrado. Revista brasileira de zootecnia, v. 30, n. 6, p. 1886-1892, 2001.

GONÇALVES, A. C. Características morfogênicas e padrões de desfolhação em pastos de capim marandu submetidos a regimes de lotação continua. 124p. Dissertação (Mestrado) - Escola Superior de Agricultura "Luis de Queiroz", Universidade de São Paulo,Piracicaba, 2002.

GORDON, L. I.; ILLIUS, A.W. Foraging strategy: from monoculture to mosaics. In: SPEEDY, A. W. (Ed.). Progress in sheep and goat research. Wallingford: CAB Iinternational, 1992. p. 153-178.

GORDON, L. I.; LASCANO, C. Foraging strategies of ruminants livestock on intensively managed grassland: potential and constrains. p. 681-690. 1993.

HODGSON, J. Grazing management. Science into Practice. Essex: Longman. 1990. 203p. 
HODGSON, J.; CLARK, D. A.; MITCHELL, R. J. Foraging behaviour in grazing animals and its impact on plant comunities. In: FAHEY, G. C. (Ed.). Forage Quality Evaluation and utilization. Lincoln: American Society of Agronomy, 1994. p. 796-827.

HULET, C. V.; ALEXANDER, G.; HAFEZ, E. S. E. The Behaviour of sjeep. In: HAFEZ, E. S. E. The behaviour of domestic animals. 3 ed. Ed. Bailliere Tindall, London, 1975, 532p.

JENSEN, P. The Ethology of Domestic Animals - An Introductory Text. Oxon: CABI Publishing, p. 147-148, 2002.

LACA, E. A.; DEMMENT, M. W. Modelling intake of a grazing ruminant in a heterogeneous environment. In: INTERNATIONAL SYMPOSIUM ON VEGETATION: HERBIVORE RELATIONSHIPS, 1992, New York. Anais...New York, 1992. p. 57-76.

LEÃO M. I. SILVA M. M. C., MAGALHÃES A. C. M. Etologia e comportamento ingestivo em caprinos e ovinos. IN: Anais... I Simpósio de Caprinos e Ovinos. EV-UFMG, Belo Horizonte, MG, Brasil, 2005.

MEDEIROS, R. B.; PEDRoso, C. E. da S.; JORNADA, J. B. J. da.; SILVA, M. A. da.; SAIBRo, J. C. Comportamento ingestivo de ovinos no período diurno em pastagem de azevém anual em diferentes estádios fenológicos. Revista Brasileira de Zootecnia, v. 36, n.1, p.198-204, 2007.

MINSON, D. J. (1990). Forage in ruminant nutrition. San Diego: Academic Press, 483p.

MONTEIRO, A. L. G., POLI, C. H. E. C.; MORAES, A. Pastagens para ovinos, Farmpoint Ovinos e Caprinos, Rede Agripoint, 30 maio 2006.2 Disponível em:<http://www.farmpoint.com.br/?noticiaID=22\&actA=7\&areaID=3\&secaoID=29 Acessado em 20 Out. 2013.

MOREIRA, J. N.; VOLTOLINI, T. V.; MOURA NETO, J. B.; SANTOS, R. D.; FRANÇA, C. A.; ARAÚJO, G. G. L. Alternativas de volumosos para caprinos em crescimento. Revista Brasileira de Saúde e Produção Animal, v. 9, n. 3, p. 407- 415, 2008.

NABINGER, C. Eficiência do uso de pastagens: disponibilidade e perdas de forragem. In: PEIXOTO, A.M.; MOURA, J.C.; FARIA, V.P. (Eds.). Fundamentos do pastejo rotacionado. Piracicaba: FEALQ, 1999. p. 213-251.

NATEL, A. S., SIQUeIRA, E. R., DIAS, T. M., AZEVEDO, G. M., MARTINS, M. B. Comportamento ingestivo de ovelhas Bergamácia alimentadas com quatro distintos teores de FDN. In: Synergismus scyentifica UTFPR, XV Simpósio Paranaense de Ovinocultura, III Simpósio Paranaense de Caprinocultura, III Simpósio Sul Brasileiro de Ovinos e Caprinos, Pato Branco, 07 (1), 2012.

NOVAIS, M. P.; DANSI, R. A.; OSS, D. B.; SOARES, F. P.; BAUER, M. O. Comportamento ingestivo de ovinos em pastagem de Brachiaria brizantha cv. Marandu manejada em diferentes alturas. XIII Encontro Latino Americano de Iniciação Científica e IX Encontro Latino Americano de Pós-Graduação - Universidade do Vale do Paraíba, 2009.

O'REAGAIN, P. J., SCHWARTZ, J. Dietary selection and foraging strategies of animals on rangeland. Coping with spatial and temporal variability. In: Recent Developments In The Nutrition Of Herbivores. International Symposium on the nutrition of herbivores, 4, Clermont-Ferrand,1995. p. 419-424.

PALHANO, A. L.; CARVALHO, P. C. de F.; BARRETO, M. Z. Influência da estrutura da pastagem na geometria do bocado e nos processos de procura e manipulação da forragem. Tuiuti: Ciência e Cultura, n. 31, p. 33-52, Curitiba, 2002.

PAULA, E. F. E.; STUPAK, E. C.; ZANATTA, C. P.; PONCHEKI, K.; LEAL, P. C.; MONTEIRO, L. G. Comportamento ingestivo de ovinos em pastagens: uma revisão. Revista Trópica Ciências Agrárias e Biológicas, v. 4, n. 1, p.43, 2010. 
PEDROSO, C. E. S.; MEDEIROS, R. B.; ABREU DA SILVA, M. et al. Comportamento de ovinos em gestação e lactação sob pastejo em diferentes estádios fenológicos de azevém anual. Revista Brasileira de Zootecnia, v.33, n.5, p.1340-1344, 2004.

PENNING, P. D.; ROOK, A. J.; ORR, R. J.; TREACHER, T. T. Intake and behavior responses by sheep to changes in sward characteristics under continuous stocking. Grass and Forage Science, Oxford, v.46, p. 15-28, 1991.

POPPI, D. P.; HUGHES, T. P.; L'HUILLIER, P.J. Intake of pasture by grazing ruminants. In: NICOL, A.M. (Ed.). Livestock feeding on pasture. Halminton: New Zealand Society of Animal Production, 1987. p. 55-64. (Occasional Publication no 10).

QUADROS, D. G. Pastagens para ovinos e caprinos. In: SIMPOGECO - SIMPÓSIO DO GRUPO DE ESTUDOS DE CAPRINOS E OVINOS - Mini-curso "PASTAGENS PARA CAPRINOS E OVINOS". 2. Salvador:UFBA. (Material didático). 34p, 2006.

RAMÍREZ, R. G. Estudios nutricionales de las cabras en el noreste de México.: Primera Parte. México: Universidad Autónoma de Nueva León, 1989. (Cuaderno de investigación, v.6).

RIBEIRO, L. R.; ÍTAVO, L. C. V.; TOLEDO, V. A. A. et al. Comportamento ingestivo de cabras Saanen em lactação em pastagem de grama estrela (Cynodon nlemfuensis). In: REUNIÃO ANUAL DA SOCIEDADE BRASILEIRA DE ZOOTECNIA, 37, 2000, Viçosa. Anais... Viçosa: Gmosis, 2000. CD-ROM. Bioclimatologia e Etologia. BIOCLIMATO-0476.

RIBEIRO, S. D. A.; RIBEIRO, A. C. Situação atual e perspectivas da caprinocultura de corte para o Brasil. In: SIMPÓSIO PAULISTA DE CAPRINOCULTURA, 1, 2005, Jaboticabal. Anais... Jaboticabal: Gráfica Multipress Ltda., 2005. p. 9-28.

RODRIGUES, M. M. Estrutura do pasto e comportamento ingestivo de caprinos em pasto de capim-tanzânia. 2010. 39f. Dissertação (Mestrado em Ciência Animal) Universidade Federal do Piauí, Teresina, 2010.

ROMAN, J. Relação Planta-animal em diferentes intensidades de pastejo com ovinos em azevém (Lolium multiflorumLam.). Santa Maria. 2006. 79p. Dissertação (Mestrado em Zootecnia) - Centro de Ciências Rurais, Universidade Federal de Santa Maria, 2006.

RUTTER, S. M.; ORR, R. J.; PENNING, P. D.; YARROW N. H.; CHAMPION R. A. Ingestive behaviour of heifers grazing monocultures of ryegrass or white clover. Applied Animal Behaviour Science,Volume 76, p.1-9, Fevereiro 2002.

SARMENTO, D. O. L. Comportamento ingestivo de bovinos em pastos de capim Marandu submetidos a regimes de lotação contínua. Piracicaba. 2003. 75p. Dissertação (Mestrado Agronomia, Ciência Animal e Pastagens) - Escola Superior de Agricultura Luiz de Queiroz, Universidade de São Paulo, 2003.

SILVA, C. J. A. Características estruturais das forrageiras aruana e hemártria e o comportamento ingestivo de caprinos em pastejo. 2006. 109f. Dissertação (Mestrado em Agronomia) - Programa de Pós-Graduação em Agronomia, Universidade Federal do Paraná, Curitiba, 2006.

SILVA, R. G. da.; NEIVA, J. N. M.; CÂNDIDO, M. J. D.; LOBO, R. N. B. Aspectos comportamentais e desempenho produtivo de ovinos mantidos em pastagens de capim Tanzânia manejado sob lotação intermitente. Ciência Animal Brasileira, v. 8, n. 4, p. 609620, 2007.

SILVEIRA, E. O. Produção e comportamento ingestivo de cordeiros em pastagem de azevém anual (Lolium multiflorum Lam) manejado a diferentes alturas. 2001. Dissertação (Mestrado em Zootecnia) - Universidade Federal do Rio Grande do Sul, Porto Alegre, 2001. 
STOBBS, T. H. The effects of plant structure on the intake of tropical pastures. II. Differences in sward Structure, nutritive value and bite size of animals grazing Setaria ancepsand Chloris gayana at various stages of growth. Australian Journal of Agricultural Research, Victoria, v.24, p. 821-829, 1973

TREVISAN, N. B.; QUADROS, F. L. F.; CORADINI, F. S.; BANDINELLI, D. G.; MARTINS, C. E. N.; SIMÕES, L. F. C.; MAIXNER, A. R.; PIRES, D. R. F. Comportamento ingestivo de novilhos de corte em pastagem de aveia preta e azevém com níveis distintos de folhas verdes. Ciência Rural, v. 34, n.5, p.1543-1548, 2004.

UNGAR, E. D. Ingestive behaviour. In: HODGSON, J.; ILLIUS, A. W. (Ed.). The Ecology and management of grazing systems. Wallingford: CAB International, 1996. p. 185-218.

VAN SOEST, P. J. Interaction of feeding behavior and forage composition. In: International Conference on Goats, 4, 1987. Proceedings... Brasília: EMBRAPA, p. 971-987, 1987.

VAN SOEST, P. J. Nutritional Ecology of the Ruminant. Nutritional Ecology of the Ruminant. 2nd. Ithaca, NY: Comstock Publishing Associates, 1994. 476 p.

VIEIRA, R.A.M.; QUEIROZ, A.C.; HENRIQUE, D.S. Padrão VAN SOEST, P.J. Nutritional ecology of the ruminant. 2 nd ed. Ithaca: Cornell University Press, 1994. 476p.

VOLTOLINI, T. V.; MOREIRA, J. N.; NOGUEIRA, D. M.; PEREIRA, L. G. R.; AZEVEDO, S. R. B.; LINS, P. R. C. Fontes protéicas no suplemento concentrado de ovinos em pastejo. Acta Scientiarum. Animal Sciences, v. 31, n. 1, p. 61-67, 2009.

WILSON, J. R. Environmental and nutricional factors affecting herbage quality. In: HACKER, J. B. (Ed.). Nutritional limits to animal production from pastures. Farnham Royal: $C A B, 1982$. p. 111-113.

ZANINE, A. M.; SANTOS, E. M.; FERREIRA, D. J.; GRAÑA, A. L. Comportamento ingestivo de ovinos e caprinos em pastagens de diferentes estruturas morfológicas. Revista Electrónica de Veterinaria REDVET, ISSN 1695-7504, V. 2, no 04, 982. p. 111-113. 